\title{
POTENSI EKSTRAK DAUN NANGKA (Artocarpus heterophyllus Lam.) SEBAGAI ANTIOKSIDAN ALAMI
}

\author{
Ni Made Rica Dwi Adnyani*, I Made Oka Adi Parwata dan I Made Sutha Negara \\ Program Studi Kimia FMIPA Universitas Udayana, Bukit Jimbaran, Bali \\ *Email: ricadwia@yahoo.com
}

\begin{abstract}
ABSTRAK
Antioksidan merupakan suatu senyawa yang mampu menangkal atau meredam efek negatif oksidan dalam tubuh. Daun nangka (Artocarpus heterophyllus Lam.) dapat digunakan sebagai antioksidan alami karena mengandung metabolit sekunder. Penelitian ini bertujuan untuk mengetahui potensi ekstrak daun nangka yang dapat digunakan sebagai antioksidan alami. Ekstraksi serbuk kering daun nangka dilakukan dengan metode maserasi menggunakan pelarut $\mathrm{n}$-heksana, etil asetat dan etanol, sedangkan uji aktivitas antioksidan dilakukan menggunakan metode difenilpikril hidrazil. Ekstraksi 1000 gram serbuk daun nangka kering menghasilkan ekstrak kental n-heksana yang berwarna hijau sebanyak 19,60 gram, ekstrak etil asetat yang berwarna hijau kecoklatan sebanyak 21,04 gram dan ekstrak etanol yang berwarna coklat sebanyak 24,76 gram. Uji fitokimia menunjukkan bahwa ekstrak n-heksana, etil asetat dan etanol positif terdapat senyawa flavonoid. Total flavonoid pada ekstrak n-heksana $18,07 \mathrm{mg} / 100 \mathrm{gr}$ QE, ekstrak etil asetat 249,94 mg/100gr QE dan ekstrak etanol 422,90 mg/100gr QE. Hasil uji aktivitas antioksidan pada ekstrak n-heksana memiliki nilai IC $_{50}$ sebesar $35,57 \mathrm{ppm}$, ekstrak etil asetat memiliki nilai IC $_{50}$ sebesar 48,48 ppm dan ekstrak etanol memiliki nilai $\mathrm{IC}_{50}$ sebesar $12,65 \mathrm{ppm}$. Hasil ini menunjukkan bahwa ekstrak etanol memiliki aktivitas antioksidan paling kuat dan siap dikembangkan sebagai alternatif antioksidan alami.
\end{abstract}

Kata kunci: antioksidan, daun nangka, $\mathrm{IC}_{50}$ (Artocarpus heterophyllus Lam.), total flavonoid

\begin{abstract}
Antioxidants are compounds that can counteract or mitigate the negative effects of oxidants in the body. Jackfruit leaf (Artocarpus heterophyllus Lam.) can be used as natural antioxidants because it contains secondary metabolites. The extraction of dry powder of jackfruit leaf was done by maceration method using n-hexane, ethyl acetate and ethanol, while the test for antioxidants activity was carried out using diphenylpicryl hydrazyl method. This study aimed to determine the potential of jackfruit leaf extract that can be used as natural antioxidants. The extraction of 1000 grams of dry powder of jackfruit leaf produced 19.60 grams concentrate green n-hexane extract, 21.04 grams concentrate brownish green ethyl acetate extract and 24.76 grams concentrate brown ethanol extract. The phytochemical test indicated that n-hexane extract, ethyl acetate extract and ethanol extract containined flavonoids compound. The total flavonoid in $\mathrm{n}$-hexane extract was $18.07 \mathrm{mg} / 100 \mathrm{gr} \mathrm{QE}$, in ethyl acetate extract was $249.94 \mathrm{mg} / 100 \mathrm{gr} \mathrm{QE}$ and in ethanol extract was $422,90 \mathrm{mg} / 100 \mathrm{gr}$ QE. The antioxidant activity test on $\mathrm{n}$-hexane extract, ethyl acetate extract and ethanol extract resulted in $\mathrm{IC}_{50}$ of $35.57 \mathrm{ppm}, 48.48 \mathrm{ppm}$ and $12.46 \mathrm{ppm}$, respectively. These results showed that the ethanol extract had an antioxidant activity of the most powerful and is ready to be developed as an alternative natural antioxidants.
\end{abstract}

Keywords: antioxidant, IC50, Jackfruit leaf (Artocarpus heterophyllus Lam.), total flavonoids

\section{PENDAHULUAN}

Stres oksidatif terjadi karena ketidakseimbangan jumlah radikal bebas dengan jumlah antioksidan endogen yang diproduksi oleh tubuh.Keadaan ini bila tidak ditanggulangi dengan baik dapat menimbulkan berbagai macam penyakit degeneratif seperti penuaan dini, kanker, diabetes, jantung dan penyakit degeneratif lainnya. Radikal bebas merupakan komponen yang kekurangan satu elektron, sehingga bersifat reaktif terhadap komponen lain untuk melengkapi kekurangan elektronnya. Adanya Radikal bebas dalam tubuh disebabkan oleh hasil samping proses oksidasi dan pembakaran sel, olahraga yang berlebih, 
peradangan, dan terpapar polusi (Murray dkk, 2009; Parwata dkk, 2016). Keadaan diatas menyebabkan tubuh memerlukan suatu asupan yaitu antioksidan.

Antioksidan merupakan senyawa yang mampu menangkal atau meredam efek negatif oksidan dalam tubuh (Ramadhan, 2015). Antioksidan endogen berdasarkan sumbernya terdiri dari dua golongan yaitu antioksidan sintetik dan antioksidan alami. Hasil penelitian Amarowicz dkk (2000) menyatakan bahwa penggunaan bahan sintetis seperti butil hidroksil anisol (BHA), butil hidroksil toluene (BHT), tert-butil hidroksil quinon (TBHQ) dan propil galat dapat meningkatkan resiko penyakit kanker. Untuk mencegah timbulnya suatu penyakit, maka konsumsi antioksidan alami harus ditingkatkan karena antioksidan alami relatif aman. Antioksidan alami dapat berupa vitamin $\mathrm{C}$, vitamin $\mathrm{A}$, vitamin $\mathrm{E}$, kartenoid, senyawa fenolik dan polifenolik seperti golongan flavonoid.

Senyawa-senyawa antioksidan alami biasanya terdapat dalam daun, bunga, buah dan sayur bagian-bagian dari tanaman. Bagian daun nangka (Artocarpus heterophyllus Lam.) dapat digunakan sebagai antioksidan alami karena mengandung metabolit sekunder. Hasil skrining fitokimia ekstrak daun nangka terdapat beberapa senyawa yaitu flavonoid, alkaloid, saponin, steroid, dan tanin (Marianne dkk, 2011). Hasil penelitian Nasution dan Rahmah (2014) menyatakan bahwa ekstrak etil asetat daun nangka tua mengandung senyawa saponin dan steroid yang memiliki nilai $\mathrm{IC}_{50}$ sebesar 778,76 ppm terhadap radikal bebas. Isolasi ekstrak etanol daun nangka diperoleh total senyawa flavonoid sebesar 7,55 mg/g (Wang dkk, 2011). Pada penelitian lain yang dilakukan oleh Omar dkk (2011) dari hasil isolasi ekstrak n-butanol daun nangka diperoleh senyawa flavonoid yaitu isokuerstin.

Berdasarkan uraian di atas, maka pada penelitian ini dilakukan uji aktivitas antioksidan dari ekstrak daun nangka. Uji aktivitas antioksidan dilakukan menggunakan metode difenilpikril hidrazil (DPPH).

\section{MATERI DAN METODE}

\section{Bahan}

Bahan uji yang digunakan pada penelitian ini yakni daun nangka (Artocarpus heterophyllus Lam.) tua yang didapat di kota Denpasar, khususnya Denpasar Selatan. Daun nangka ini telah dideterminasi di UPT Balai Konservasi Tumbuhan Kebun Raya Eka Karya Bali. Bahan kimia yang digunakan antara lain nheksan teknis, etil asetat teknis, etanol 96\% teknis, etanol p.a, kuersetin, DPPH (difenilpikril hidrazil), $\mathrm{NaOH}$, serbuk $\mathrm{Mg}, \mathrm{HCl}$ pekat, $\mathrm{AlCl}_{3}$, $\mathrm{H}_{2} \mathrm{SO}_{4}$ pekat, akuades.

\section{Peralatan}

Alat yang digunakan meliputi blender, neraca analitik, penangas air, oven, alat vortex, plat tetes, gelas beker,pipet mikro, kertas saring, aluminium foil, batang pengaduk, labu ukur, pipet ukur, corong gelas, penguap putar vakum (rotary vacuum evaporator), pipet tetes, tabung reaksi.

\section{Cara Kerja}

\section{Penyiapan bahan penelitian}

Daun nangka tua dicuci bersih dalam satu wadah kemudian dikering anginkan dan diblender hingga diperoleh sampel daun nangka dalam bentuk serbuk.

\section{Ekstraksi sampel}

Sebanyak 1000 gram serbuk daun nangka yang telah dihaluskan dimaserasi dengan pelarut n-heksana, etil asetat dan etanol.Maserasi masing-masing dilakukan selama $3 \times 24$ jam, lalu filtrat yang diperoleh dikumpulkan dan dievavorasi menggunakanrotary evaporator (pada suhu $50^{\circ} \mathrm{C}$ ) sehingga didapat ekstrak pekat n-heksana. Residu yang sudah dikeringkan dari hasil maserasi dengan pelarut n-heksana kemudian dimaserasi berturut-turut dengan pelarut etil asetat dan etanol. Dengan prosedur dan perlakuan yang sama, sehingga diperoleh ekstrak pekat etil asetat dan ekstrak pekat etanol.

\section{Uji fitokimia Flavonoid}

Uji fitokimia senyawa golongan flavonoid dilakukan pada ekstrak daun nangka hasil maserasi dengan menggunakan uji Bate 
Smith-Metcalfe, uji Wilstatter dan uji $\mathrm{NaOH}$ 10\% (Parwata dkk, 2016)

Uji total flavonoid ekstrak n-heksana, etil asetat dan etanol daun nangka

a. Pembuatan larutan standar kuersetin

Ditimbang $1 \mathrm{mg}$ baku standar kuersetin dan dilarutkan dalam $10 \mathrm{~mL}$ etanol sehingga di dapatkan konsentrasi 100 ppm. Larutan standar kemudian dibuat variasi konsentrasi dengan cara dipipet $10 \mu \mathrm{L}$ dan ditambahkan etanol $490 \mu \mathrm{L}$ dalam tabung 1, pada tabung 2 ditambahkan 20 $\boldsymbol{\mu} \mathrm{L}$ standar dan $480 \boldsymbol{\mu} \mathrm{L}$, pada tabung 3 ditambahkan $60 \mu \mathrm{L}$ standar dan etanol $440 \mu \mathrm{L}$, pada tabung 4 ditambahkan $80 \mu \mathrm{L}$ standar dan etanol $420 \mu \mathrm{L}$, pada tabung 5 ditambahkan 100 $\boldsymbol{\mu} \mathrm{L}$ standar dan etanol sebanyak $400 \boldsymbol{\mu} \mathrm{L}$ sedangkan pada tabung 6 (blanko) dipipet 500 $\boldsymbol{\mu} \mathrm{L}$ etanol (tanpa penambahan sampel). Masingmasing variasi konsentrasi kemudian ditambahkan $500 \mu \mathrm{L} \quad \mathrm{AlCl}_{3}$.Sampel kemudian diinkubasi dalam waktu 30 menit dan serapan dari larutan standar diukur pada panjang gelombang $415 \mathrm{~nm}$.

b. Analisis ekstrak daun nangka

Sebanyak 0,1 gram masing-masing ekstrak n-heksana, etil asetat dan etanol ditimbang. Sampel selanjutnya dilarutkan ke dalam labu ukur $5 \mathrm{~mL}$ menggunakan etanol 50\% dan disaring. Filtrat yang dihasilkan kemudian direaksikan dengan $\mathrm{AlCl}_{3}$ dengan perbandingan 1:1 dengan cara $250 \boldsymbol{\mu} \mathrm{L}$ ekstrak dipipet dan ditambahkan sebanyak $250 \mu \mathrm{L}$ etanol $50 \%$. Ekstrak tersebut dimasukkan pada tabung reaksi kemudian ditambahkan $500 \mu \mathrm{L}$ larutan $\mathrm{AlCl}_{3}$. Larutan kemudian dihomogenkan dan didiamkan selama 30 menit. Pengukuran absorbansi kemudian dilakukan pada panjang gelombang $415 \mathrm{~nm}$.

\section{Uji aktivitas antioksidan terhadap DPPH}

Uji aktivitas antioksidan dilakukan dengan menguji larutan sampel (ekstrak daun nangka yang positif mengandung flavonoid dan hasil isolasi golongan flavonoid). Larutan induk ekstrak daun nangka yakni 1000 ppm. Larutan induk ekstrak daun nangka dipipet sebanyak 16 $\mu \mathrm{L} ; 24 \mu \mathrm{L} ; 32 \mu \mathrm{L} ; 40 \mu \mathrm{L}$; dan $80 \mu \mathrm{L}$ ke dalam tabung reaksi, kemudian volume dicukupkan sebanyak $4 \mathrm{~mL}$ dengan etanol p.a lalu dihomogenkan dengan alat vortex untuk mendapatkan konsentrasi larutan uji 4 ppm, 6 ppm, 8 ppm, 10 ppm dan 20 ppm. Ke dalam masingmasing tabung ditambahkan $1 \mathrm{~mL}$ larutan DPPH 0,1 mM, lalu dihomogenkan. Larutan sampel dengan berbagai konsentrasi pada ekstrak diinkubasi selama 30 menit. Larutan blanko dibuat dengan cara DPPH $0,1 \mathrm{mM}$ dipipet sebanyak $1 \mathrm{~mL}$ kemudian dimasukkan ke dalam tabung reaksi lalu ditambahkan $4 \mathrm{~mL}$ etanol p.a, kemudian dihomogenkan. Serapan dari masingmasing sampel diukur pada panjang gelombang $517 \mathrm{~nm}$.

\section{HASIL DAN PEMBAHASAN}

\section{Penentuan kadar air}

Serbuk kering daun nangka memiliki presentase kadar air sebesar 5,7\%, hal ini menunjukkan bahwa persentase kadar air dalam serbuk kering daun nangka tua tergolong memenuhi syarat. Kadar air dalam ekstrak/simplisia tidak boleh lebih dari $10 \%$ (Sudarmadji, 2003).

\section{Ekstraksi daun nangka}

Proses maserasi serbuk kering daun nangka tua dilakukan secara gradien. Ekstraksi pertama daun nangka menggunakan $4500 \mathrm{~mL} \mathrm{n-}$ heksana dihasilkan ekstrak kental n-heksana sebanyak 19,60 gram yang berwarna hijau. Ekstraksi kedua daun nangka menggunakan $3500 \mathrm{~mL}$ etil asetat dihasilkan ekstrak kental etil asetat sebanyak 21,04 gram yang berwarna hijau kecoklatan. Ekstraksi ketiga daun nangka menggunakan $4000 \mathrm{~mL}$ dihasilkan ekstrak kental etanol sebanyak $24,76 \mathrm{~g}$ yang berwarna coklat. Masing-masing ekstrak kental yang diperoleh diuji kandungan flavonoid dan diuji total senyawa flavonoid, sehingga diperoleh hasil seperti yang dipaparkan pada Tabel 1 . 
Tabel 1. Hasil uji flavonoid, total flavonoid, dan perolehan berat dari ekstrak n-heksana, etil asetat, dan ekstrak etanol

\begin{tabular}{|c|c|c|c|c|c|c|c|}
\hline \multirow[t]{2}{*}{ Ekstrak } & \multirow{2}{*}{$\begin{array}{l}\text { Berat } \\
\text { (gram) }\end{array}$} & \multirow[b]{2}{*}{$\begin{array}{c}\text { Total } \\
\text { flavonoi } \\
\mathrm{d} \\
(\mathrm{mg} / \\
100 \mathrm{gr} \\
\mathrm{QE})\end{array}$} & \multicolumn{3}{|c|}{ Uji Warna } & \multirow{2}{*}{$\begin{array}{l}\text { Golongan flavonoid } \\
\text { yang diduga dengan } \\
\text { pereaksi } \mathrm{NaOH} 10 \%\end{array}$} & \multirow[t]{2}{*}{ Ket } \\
\hline & & & $\begin{array}{c}\mathrm{NaOH} \\
10 \%\end{array}$ & $\begin{array}{c}\mathrm{H}_{2} \mathrm{SO}_{4} \\
\text { pekat } \\
\text { dipanaskan } \\
\text { (Uji Bate- } \\
\text { Smith } \\
\text { Metcalfe) }\end{array}$ & $\begin{array}{c}\mathrm{Mg}-\mathrm{HCl} \\
\quad(\mathrm{Uji} \\
\text { Wilstatter) }\end{array}$ & & \\
\hline n-heksana & 19,60 & 18,07 & Kuning & Hijau & Hijau & $\begin{array}{c}\text { Flavon, isoflavon atau } \\
\text { isoflavonon }\end{array}$ & + \\
\hline \multirow{2}{*}{$\begin{array}{l}\text { etil asetat } \\
\text { etanol }\end{array}$} & 21,04 & 249,94 & $\begin{array}{l}\text { Kuning } \\
\text { muda }\end{array}$ & Merah tua & Hijau & $\begin{array}{c}\text { Dihidroksikalkon atau } \\
\text { flavononol }\end{array}$ & ++ \\
\hline & 24,76 & 422,90 & Orange & Orange & Merah & $\begin{array}{c}\text { Khalkon, flavonon } \\
\text { atau flavonol }\end{array}$ & +++ \\
\hline
\end{tabular}

Keterangan: +++: Intensitas kandungan flavonoid sangat tinggi

++ : Intensitas kandungan flavonoid tinggi

+ : Intensitas kandungan flavonoid rendah

Pada Tabel 1 menunjukkan ekstrak nheksana, etil asetat, dan etanol positif mengandung flavonoid. Ekstrak etanol positif terhadap ketiga pereaksi flavonoid tersebut yang menghasilkan perubahan warna yang khas untuk senyawa flavonoid dan memiliki intensitas warna yang kuat jika dibandingkan dengan ekstrak n-heksana dan etil asetat. Hal ini juga didukung dengan diperolehnya total flavonoid ekstrak etanol sebesar 422,90 mg/100gr QE, sedangkan untuk ekstrak n-heksana dan etil asetat masing-masing diperoleh total flavonoid sebesar 18,07 mg/100gr QE dan 249,94 mg/100gr QE. Ekstrak n-heksana, etil asetat dan etanol dilanjutkan uji aktivitas antioksidannya.

\section{Uji aktivitas antioksidan ekstrak daun nangka}

Ekstrak n-heksana, etil asetat dan etanol yang positif senyawa flavonoid diukur aktivitas antioksidannya secara spektrofotometri UV-Vis dengan metode DPPH. Hasil pengukuran absorbansi pada panjang gelombang $517 \mathrm{~nm}$ dari ekstrak n-heksana, etil asetat dan etanol yang dibuat dengan beberapa variasi kadar memberikan hasil uji aktivitas antioksidan seperti yang ditampilkan pada Tabel 2 .

Pada Tabel 2 dapat dilihat bahwa seiring dengan penambahan ekstrak ke dalam larutan DPPH $0,1 \quad \mathrm{mM}$, nilai absorbansi DPPH mengalami penurunan dibandingkan dari absorbansi blanko. Penurunan absorbansi disebabkan tereduksinya molekul DPPH oleh senyawa antioksidan dalam ekstrak. Penurunan absorbansi juga diikuti dengan berkurangnya intensitas warna ungu dari larutan DPPH. Nilai $\mathrm{IC}_{50}$ yang diperoleh pada ekstrak n-heksana sebesar 35,57 ppm, ekstrak etil asetat sebesar 48,48 ppm dan ekstrak etanol sebesar 12,65 ppm. Ekstrak etanol memiliki nilai $\mathrm{IC}_{50}$ paling kecil sehingga dapat dikatakan memiliki aktivitas antioksidan paling kuat.

Berdasarkan hasil uji flavonoid, total flavonoid dan uji aktivitas antioksidan menunjukkan bahwa ekstrak etanol memiliki total flavonoid paling besar dan aktivitas antioksidan paling kuat dengan nilai $\mathrm{IC}_{50}$ paling kecil dibandingkan dengan ekstrak n-heksana dan etil asetat. Hal ini menunjukkan bahwa ekstrak etanol dapat dipergunakan sebagai antiokasidan alami. 
Tabel 2. Hasil uji aktivitas antioksidan ekstrak n-heksana, etil asetat dan etanol

\begin{tabular}{|c|c|c|c|c|c|c|}
\hline \multirow[t]{2}{*}{ Sample } & \multirow{2}{*}{$\begin{array}{c}\text { Konsentrasi } \\
(\mathrm{mg} / \mathrm{L})\end{array}$} & \multicolumn{2}{|c|}{ Absorbansi } & \multirow[t]{2}{*}{$\%$ inhibisi } & \multirow{2}{*}{$\begin{array}{l}\text { Persamaan } \\
\text { linier }\end{array}$} & \multirow{2}{*}{$\begin{array}{c}\mathrm{IC}_{50} \\
(\mathrm{mg} / \mathrm{L})\end{array}$} \\
\hline & & blanko & $\begin{array}{c}\text { Sample } \\
\text { uji }\end{array}$ & & & \\
\hline Ekstrak & 4 & & 0,192 & 5,88 & $y=1,2496 x+$ & \\
\hline \multirow[t]{4}{*}{ n-heksana } & 6 & & 0,177 & 13,23 & 5,552 & \\
\hline & 8 & 0,204 & 0,171 & 16,18 & $\mathrm{R}^{2}=0,7739$ & 35,57 \\
\hline & 10 & & 0,154 & 24,51 & & \\
\hline & 20 & & 0,147 & 27,94 & & \\
\hline Ekstrak & 4 & & 0,211 & 4,09 & $y=0,9285 x+$ & \\
\hline \multirow[t]{4}{*}{ etil asetat } & 6 & & 0,194 & 11,82 & 4,9948 & \\
\hline & 8 & 0,220 & 0,187 & 15,00 & $\mathrm{R}^{2}=0,7739$ & 48,48 \\
\hline & 10 & & 0,183 & 16,82 & & \\
\hline & 20 & & 0,172 & 21,81 & & \\
\hline Ekstrak & 4 & & 0,160 & 27,93 & $y=2,7201 x+$ & \\
\hline \multirow[t]{4}{*}{ etanol } & 6 & & 0,150 & 32,43 & 15,597 & \\
\hline & 8 & 0,222 & 0,148 & 33,33 & $\mathrm{R}^{2}=0.9813$ & 12.65 \\
\hline & 10 & & 0,123 & 44,59 & & \\
\hline & 20 & & 0,066 & 70,27 & & \\
\hline
\end{tabular}

\section{SIMPULAN DAN SARAN}

\section{Simpulan}

Nilai $\mathrm{IC}_{50}$ yang diperoleh pada ekstrak nheksana sebesar 35,57 ppm, ekstrak etil asetat sebesar 48,48 ppm dan ekstrak etanol sebesar $12,65 \mathrm{ppm}$. Ekstrak etanol memiliki nilai $\mathrm{IC}_{50}$ paling kecil sehingga dapat dikatakan memiliki aktivitas antioksidan paling kuat dan dapat dikembangkan sebagai antioksidan alternatif yang berasal dari alam.

\section{Saran}

Perlu dilakukannya penelitian lanjutan terhadap senyawa yang memiliki aktivitas antioksidan pada daun nangka (Artocarpus heterophyllus Lam.) dan mengidentifikasi senyawa aktif untuk mengetahui struktur dari senyawa yang aktif sebagai antioksidan.

\section{UCAPAN TERIMA KASIH}

Penulis menyampaikan terimakasih banyak kepada semua pihak atas saran dan masukan serta yang turut membantu dalam proses penyelesaian penelitian ini.

\section{DAFTAR PUSTAKA}

Amarowicz, R., Naczk, M., and Shahidi, F., 2000, Antioxidant Activity of Crude Tannins of Canola and Rapeseed Hulls, JAOCS, 77: 957-961

Marianne, Yuandani, dan Rosnani, 2011, Antidiabetic Activity From Ethanol Extract Of Kluwih's Leaf (Artocarpus Camansi), Jurnal Natural, 11 (2): 64-68

Murray R.K., Granner D.K., and Rodwell V.W., 2009, Biokimia Harper, Diterjemahkan Oleh Andri Hartono, Edisi 27, Penerbit Buku Kedokteran, EGC, Jakarta

Nasution, H., dan Rahmah, M., 2014, Pengujian Antiradikal Bebas Difenilpikril Hidrazil (DPPH) Ekstrak Etil Asetat Daun Nangka (Artocarpus heterophyllus Lam.), J. Sains Dasar, 3 (2): 134-141

Omar, S.H., El-Beshbishy, H.A., Moussa, Z., Taha, K.F., and Singab, A.N.B., 2011, Antioxidant Activity of Artocarpus heterophyllus Lam. (Jack Fruit) Leaf Extracts: Remarkable Attenuations of Hyperglycemia and Hyperlipidemia in Streptozotocin-Diabetic Rats, The Scientific Word Journal, 788-800 
Parwata, A., Sukardiman, Mulya H.S., and Alit Widhiartini, 2016, Inhibition of Fibrosarcoma Growth by 5-Hydroxy-7Ethoxy-Flavanons from Kaempferia pandurata Roxb, Biomedical \& Pharmacology Journal,9(3) : 941-948.

Ramadhan, P., 2015, Mengenal Antioksidan, Cetakan Pertama, Graha Ilmu, Yogyakarta

Sabuea, P., 2003, Antioksidan Senyawa Ajaib Penangkal Penuaan Dini, Sinar Harapan, Yogyakarta
Sudarmadji, S., 2003, Analisa Bahan Makanan dan Pertanian, Edisi ke 2, Vol. III, Liberty, Yogyakarta

Wang, H.W., Liu, Y.Q., and Wang, Y.H., 2011, Optimization of Ultrasonic-Assisted Extraction of Total Flavonoids From Leaves Of The Artocarpus heterophyllus by Response Surface Methodology, Zhong Yao Cai, 23 (7): 1125-1129 